\title{
Optimizing the synthesis of cobalt-based catalysts for the selective growth of multiwalled carbon nanotubes under industrially relevant conditions
}

\author{
M. J. Becker ${ }^{\text {a }}$, W. Xia ${ }^{\text {a }}$, J.-P. Tessonnier ${ }^{\text {b }}$, R. Blume ${ }^{\text {b }}$, L. Yao ${ }^{\text {b }}$, R. Schlögl ${ }^{\text {b }}$, M. Muhler ${ }^{\text {a } *}$ \\ ${ }^{a}$ Laboratory of Industrial Chemistry, Ruhr-University Bochum, D-44780 Bochum, Germany \\ ${ }^{b}$ Department of Inorganic Chemistry, Fritz Haber Institute of the Max Planck Society, D-14195 Berlin, Germany \\ "Corresponding author: e-mail muhler@techem.rub.de,
}

Received 11 May 2011; Accepted 22 July 2011. Available online 4 August 2011

\begin{abstract}
A An industrially applicable cobalt-based catalyst was optimized for the production of multiwalled carbon nanotubes (CNTs) from ethene in a hot-wall reactor. A series of highly active Co-Mn-Al-Mg spinel-type oxides with systematically varied Co : Mn ratios was synthesized by precipitation and calcined at different temperatures. The addition of Mn drastically enhanced the catalytic activity of the Co nanoparticles resulting in an extraordinarily high CNT yield of up to $249 \mathrm{~g}_{\mathrm{CNT}} / \mathrm{g}_{\mathrm{Cat}}$. All quaternary catalysts possessed an excellent selectivity towards the growth of CNTs. The detailed characterization of the obtained CNTs by electron microscopy, Raman spectroscopy and thermogravimetry demonstrated that a higher Mn content results in a narrower CNT diameter distribution, while the morphology of the CNTs and their oxidation resistance remains rather similar. The temperature-programmed reduction of the calcined precursors as well as in-situ X-ray absorption spectroscopy investigations during the growth revealed that the remarkable promoting effect of the $\mathrm{Mn}$ is due to the presence of monovalent $\mathrm{Mn}$ (II) oxide in the working catalyst, which enhances the catalytic activity of the metallic Co nanoparticles by strong metal-oxide interactions. The observed correlations between the added Mn promotor and the catalytic performance are of high relevance for the production of CNTs on an industrial scale.
\end{abstract}

\section{Introduction}

Multiwalled carbon nanotubes (CNTs) are of great interest because of their corrosion resistance, high electric and heat conductivity, and high mechanical strength [1-3]. Since the last two decades numerous potential applications have been investigated, for instance in heterogeneous catalysis [4], as a direct replacement for carbon black in composites [5], and in electrochemistry [6]. The large-scale application of CNT-based materials requires their low-cost production on an industrial scale. Catalytic chemical vapor deposition (CCVD) of hydrocarbons over Fe-, Co- or Nibased catalysts is the most promising and thus most widely used synthesis route for large-scale CNT production [7-9]. The synthesis of highly active catalysts and the growth mechanisms of CNTs have been investigated and discussed in recent studies $[10,11]$.
Various oxides can be used as support or as structural promoter to enhance the dispersion of the active phase such as Co nanoparticles and to improve the yield of CNTs [1216]. The catalytic system for CNT synthesis can be considered as sacrificial catalyst, where both the active phase and the oxidic components remain in the product as impurities. Purification can be performed by leaching with suitable solutions such as $\mathrm{HCl}$ and/or $\mathrm{NaOH}$. However, the purification is a multi-step, energy-consuming and thus costly process. Moreover, the degree of CNT agglomeration can be changed significantly during washing and filtration [17]. The only way to avoid the purification step during the large-scale production is to improve the activity of the catalyst and, consequently, the CNT yield, because then the inorganic residues in the CNT products become negligible. A high purity and quality allows the direct employment of the CNTs in further processing [18]. 
Furthermore, the synthesis of the catalysts has to be based on readily available chemicals and unit operations to render the large-scale production of CNTs economically feasible. Thus, the catalyst synthesis by precipitation is advantageous, because the important parameters such as concentration, stirring speed, $\mathrm{pH}$ value, and aging time can be easily controlled in a one-pot synthesis. For example, Rao et al. [19] synthesized CNTs from methane over reduced $\mathrm{Mg}_{1-\mathrm{x}} \mathrm{Co}_{\mathrm{x}} \mathrm{Al}_{2} \mathrm{O}_{4}(\mathrm{x}=0.1-0.4)$ spinel catalysts with high yields and superior qualities. Co- and Mn-based mixed oxides were used in various catalytic reactions, such as the Fischer-Tropsch synthesis [20-22], the decomposition of nitrous oxide $[23,24]$, and the oxidation of volatile organic compounds [25]. As an effective promoter, Mn can significantly enhance the performance of Co catalysts.

In this study, we report on the promoting effect of $\mathrm{Mn}$ on $\mathrm{Co}$ in a quaternary mixed-oxide catalyst for CNT growth. The catalysts containing $\mathrm{Co}, \mathrm{Mn}, \mathrm{Al}$, and $\mathrm{Mg}$ were synthesized by a well-controlled precipitation method using nitrate salts $[26,27]$. The remarkable ability of this catalyst to generate well-dispersed Co nanoparticles during reduction, the exceptional high CNT yield and high selectivity towards homogeneous CNTs favor its application in largescale production [27]. The Co : Mn ratio was varied systematically, and the performance of the obtained mixed oxides and the influence of the calcination temperature of the catalyst precursor were studied in detail to elucidate the influence of $\mathrm{Mn}$ on the catalytic activity.

Nitrogen physisorption, temperature-programmed reduction (TPR), high-resolution transmission electron microscopy (TEM), scanning electron microscope (SEM), Raman spectroscopy, X-ray diffraction (XRD), X-ray adsorption spectroscopy (XAS), and thermogravimetry (TG) were employed to derive structure-activity correlations.

\section{Experimental}

The Co-Mn-Al-Mg mixed oxide catalysts were synthesized by the precipitation of their nitrates with sodium hydroxide. Either the Co content or the Mn content was varied, while keeping the molar ratio of the other three metals constant at $\mathrm{x}(\mathrm{Co}$ or $\mathrm{Mn}): 0.8(\mathrm{Al}): 1.0(\mathrm{Mg})$. The samples obtained were denoted as CoxMn3 or Co3Mnx (x $=0 ; 1 ; 2 ; 3)$ corresponding to the molar ratio of Co to $\mathrm{Mn}$. The details of the synthesis are described below with Co3Mn3 as an example:

A volume of $50 \mathrm{ml}$ of demineralized water (HPLC grade) was filled in a three-neck-flask. A mixture of $1.925 \mathrm{~g} \quad \mathrm{Co}\left(\mathrm{NO}_{3}\right)_{2} \cdot 6 \mathrm{H}_{2} \mathrm{O} \quad(99.999 \%), \quad 1.66 \mathrm{~g}$ $\mathrm{Mn}\left(\mathrm{NO}_{3}\right)_{2} \cdot \mathrm{xH}_{2} \mathrm{O} \quad(\mathrm{x}=4-6, \quad 99.99 \%), \quad 0.60 \mathrm{~g}$ $\mathrm{Al}\left(\mathrm{NO}_{3}\right)_{3} \cdot 9 \mathrm{H}_{2} \mathrm{O}(99.997 \%)$ and $0.51 \mathrm{~g} \mathrm{Mg}\left(\mathrm{NO}_{3}\right)_{2} \cdot 6 \mathrm{H}_{2} \mathrm{O}$ (99.999\%) (Sigma Aldrich) was dissolved in $8.5 \mathrm{ml}$ water (HPLC grade). The obtained red solution was pumped by a syringe pump with a flow rate of $1 \mathrm{ml} \mathrm{min}^{-1}$ into the threeneck-flask and precipitated by a 7.5 molar sodium hydroxide solution at room temperature. During precipitation the $\mathrm{pH}$ was kept at 10 by an autotitrator (Schott, alpha line).
The obtained brownish suspension was continuously stirred with a rotation speed of $180 \mathrm{rpm}$. After the nitrate solution had been added completely, the suspension was stirred additionally for $5 \mathrm{~min}$, filtered and washed with demineralized water twice. The catalyst precursor was dried in air at $453 \mathrm{~K}$ for $12 \mathrm{~h}$ in a heating cabinet. After drying the catalyst was calcined in a flow of $100 \mathrm{ml} \mathrm{min}^{-1}$ synthetic air $\left(20.5\right.$ vol. $\% \mathrm{O}_{2}$ in $\mathrm{N}_{2}$ ) at $673 \mathrm{~K}$ for $4 \mathrm{~h}$ resulting in black powders. All flow rates refer to standard temperature and pressure of $273 \mathrm{~K}$ and 1013 mbar, respectively. The obtained samples were pressed and pelletized, and the sieve fraction of 250 to $355 \mu \mathrm{m}$ was used for CNT growth.

In order to investigate the influence of the calcination temperature, the Co3Mn3 precursor was calcined at $773 \mathrm{~K}$, $873 \mathrm{~K}$ or $973 \mathrm{~K}$ in addition to the above-mentioned temperature of $673 \mathrm{~K}$.

The CNTs were grown in a flow setup consisting of a three-zone electrical furnace and a horizontal quartz tube reactor with a length and an inner diameter of $1000 \mathrm{~mm}$ and $33 \mathrm{~mm}$, respectively. The feed gases had purities of $99.9999 \%(\mathrm{He}), 99.9999 \%\left(\mathrm{H}_{2}\right)$ and $99.95 \%\left(\mathrm{C}_{2} \mathrm{H}_{4}\right)$. Typically, about $10 \mathrm{mg}$ of catalyst were placed in a quartz boat inside the isothermal region of the quartz reactor. The catalyst was reduced in $\mathrm{H}_{2}\left(50\right.$ vol. $\% \mathrm{H}_{2}$ in $\mathrm{He}, 100 \mathrm{ml} \mathrm{min}^{-1}$ total flow) applying a heating rate of $10 \mathrm{~K} \mathrm{~min}^{-1}$ from room temperature to $923 \mathrm{~K}$. After that, the CNT synthesis was carried out in a feed gas mixture of 57 vol. $\% \mathrm{C}_{2} \mathrm{H}_{4}$ and 43 vol. \% $\mathrm{H}_{2}$ with total flow rate of $100 \mathrm{ml} \mathrm{min}^{-1}$ at $923 \mathrm{~K}$ for $120 \mathrm{~min}$. After cooling down to room temperature in flowing He the sample was removed from the reactor and weighed. The weight-based CNT yield $\left(\mathrm{Y}_{\mathrm{CNT}}\right)$ was calculated according to equation (1), where $\mathrm{m}_{\text {sample }}$ is the total mass of the sample after $\mathrm{CNT}$ growth, and $\mathrm{m}_{\text {cat }}$ is the initial mass of the catalyst before reduction. The intrinsic yield (equation 2$)$ is related to the absolute mass of cobalt $\left(\mathrm{m}_{\mathrm{Co}}\right)$, which was calculated based on the Co content of the catalyst determined by elemental analysis and the total sample mass $\left(\mathrm{m}_{\text {sample }}\right)$.

$$
\begin{aligned}
\mathrm{Y}_{\mathrm{CNT}} & =\frac{\mathrm{m}_{\text {sample }}-\mathrm{m}_{\mathrm{cat}}}{\mathrm{m}_{\mathrm{cat}}} \\
\mathrm{Y}_{\mathrm{CNT}}^{\mathrm{Co}} & =\frac{\mathrm{m}_{\text {sample }}-\mathrm{m}_{\mathrm{cat}}}{\mathrm{m}_{\mathrm{Co}}}
\end{aligned}
$$

For elemental analysis atomic absorption spectroscopy (AAS) was carried out with a SpectrAA 220 (Varian) spectrometer. The catalysts were dried overnight at $383 \mathrm{~K}$ to achieve complete removal of weakly bound water. The dried catalyst was dissolved in aqua regia for elemental analysis. To avoid reactions of the $\mathrm{Mg}$ and $\mathrm{Al}$ ions, the solutions were stabilized using a $\mathrm{La}-\mathrm{Cs}$ buffer. For the analysis of $\mathrm{Mn}, \mathrm{Al}, \mathrm{Mg}$ and $\mathrm{Na}$ the corresponding hollow cathode lamps were used, and the analysis of Co was performed in the emission mode. 
The calcined catalysts were analyzed at room temperature by XRD using a PANalytical X'pert PD diffractometer equipped with a PW-30 $11 / 10$ detector, $1 / 4^{\circ}$ divergent slits, a $0.2 \mathrm{~mm}$ high receiving slit, incident and diffracted beam $0.5^{\circ}$ soller slits, a secondary graphite monochromator, and a rotating sample holder. $\mathrm{CuK} \alpha$ radiation was provided by a $45 \mathrm{~kW} \mathrm{Cu}$ tube. The diffraction patterns were recorded with a $0.035^{\circ}(2 \Theta)$ step scan and $20 \mathrm{~s}$ scanning time in the range of $12^{\circ}-70^{\circ}$. Powder diffraction files (PDF) from the International Centre of Diffraction Data (ICDD) were used for qualitative phase analysis.

TPR experiments were preformed in a flow set-up using 4.54 vol. $\% \mathrm{H}_{2}$ in Ar at a flow rate of $84.1 \mathrm{ml} \mathrm{min}^{-1}$. The reactor was heated from room temperature to $1023 \mathrm{~K}$ with a rate of $5 \mathrm{~K} \mathrm{~min}^{-1}$ and held for $120 \mathrm{~min}$ at the maximum temperature before cooling down. About $50 \mathrm{mg}$ of the sample were applied for each measurement. The hydrogen content in the evolved gases was analyzed by a thermal conductivity detector (Hydros, Fisher-Rosemount). For optimum conditions of the experiment the criteria derived by Monti and Baiker [28] were applied.

For the TG measurements the CNTs were pretreated with diluted nitric acid in order to remove the residual catalyst. About $50 \mathrm{mg}$ of the CNT sample were suspended in 50 $\mathrm{ml}$ of nitric acid $\left(1.0 \mathrm{~mol} \mathrm{l}^{-1}\right)$. After stirring the suspension for $72 \mathrm{~h}$ at room temperature the CNTs were filtered, washed with demineralized water and dried at $60^{\circ} \mathrm{C}$ for 24 h. The TG measurements were performed using a Cahn TG 2131 thermobalance coupled with a quadrupole mass spectrometer (QMS, Balzer, Omnistar). Typically $30 \mathrm{mg}$ of the pretreated samples were heated to $1023 \mathrm{~K}$ at a rate of $5 \mathrm{~K}$ $\min ^{-1}$ in $\mathrm{O}_{2}(20$ vol. \%) diluted in He with a total flow of $100 \mathrm{ml} \mathrm{min}^{-1}$. The gases had purities of $99.998 \%\left(\mathrm{O}_{2}\right)$ and $99.99 \%(\mathrm{He})$. The mass fragments of $\mathrm{m} / \mathrm{e}=18,28,32$ and 44 were monitored by the QMS.

Static $\mathrm{N}_{2}$ physisorption measurements were carried out at $77 \mathrm{~K}$ using an Autosorb-1 MP Quantachrome system. Samples were treated at $573 \mathrm{~K}$ for $2 \mathrm{~h}$ before the measurements. The data were analyzed according to the BET equation assuming an area of $0.162 \mathrm{~nm}^{2}$ per $\mathrm{N}_{2}$ molecule. The pore size distribution was derived using the BJH method. A Dilor Labram 1 spectrometer was used to record Raman spectra. A He-Ne-laser (632.8 nm, Melles Griot, $17 \mathrm{~mW}$ ) was used for excitation. The laser light was focused onto the sample using a 100x long distance objective lens (Olympus). The intensities were determined graphically using the fitting method developed by Sadezky et al. [29] using a commercial fitting software (Origin 6.1G, OriginLab cooperation).

The homogeneity of the samples was checked with a Hitachi S-4800 scanning electron microscope (FE-SEM). The samples were loosely dispersed on conductive carbon tape to preserve the as-prepared morphology as much as possible. All images were acquired using an acceleration voltage of $1.5 \mathrm{kV}$ for better resolution of surface features. About 330 carbon nanotubes were measured with the MediaCybernetics Image-Pro software. Statistics were calculated with the Origin 7.5 software. The microstructure of the reduced catalyst was investigated by high-resolution transmission electron microscopy (HRTEM) using a Philips CM200 FEG TEM operated at $200 \mathrm{kV}$. After reduction, the sample was transferred into a glove box without any contact to air. The TEM specimen was prepared by dry deposition in the glove box. After grinding the sample, a small amount of powder was directly deposited on a copper grid covered with a thin holey carbon film. The grid was then mounted on an air-tight transfer holder and then inserted in the TEM within a few minutes. The microstructure of the produced carbon nanotubes was investigated with the same microscope. The CNT sample was dispersed in chloroform and deposited on a holey carbon film supported on a $\mathrm{Cu}$ grid.

X-ray absorption spectroscopy (XAS) experiments were performed at the ISISS beamline of the FHI located at the BESSY II synchrotron facility in Berlin. The highpressure setup consisted mainly of a reaction cell attached to a set of differentially pumped electrostatic lenses and a differential pumped analyzer (Phoibos 150, SPECS $\mathrm{GmbH})$, which is described elsewhere [30].

The samples were heated from the back to $453 \mathrm{~K}$ using an external IR-laser (cw, $808 \mathrm{~nm}$ ) to compensate for charging. The temperature was controlled via a K-type thermocouple in direct contact with the sample surface.

Sample contamination was checked by survey spectra in the range of 1000 to $0 \mathrm{eV}$ at the beginning of each experiment. The XAS spectra of the Mn LMM edges were recorded in the Total Electron Yield (TEY) mode enhanced by additional electrons created by ionization of the gas phase above the sample ( $\mathrm{Ar}, \mathrm{H}_{2}$ and $\mathrm{C}_{2} \mathrm{H}_{4}$ for the calcined, reduced and cooled sample, respectively).

\section{Results and discussion}

\subsection{Elemental analysis, $N_{2}$ physisorption and $X$ - ray diffraction}

The Co : Mn ratio was systematically varied in order to study the impact of $\mathrm{Mn}$ on the structure of the mixed oxide catalysts and their catalytic activities. The mass fractions of $\mathrm{Co}, \mathrm{Mn}, \mathrm{Al}$ and $\mathrm{Mg}$ were determined by AAS after calcination in synthetic air at $673 \mathrm{~K}$. The results are summarized in Table 1 . Only traces $(<0.03 \mathrm{wt}-\%)$ of sodium were detected originating from the precipitation agent $\mathrm{NaOH}$. The complete removal of remaining nitrates after calcination was confirmed by TG studies (not shown), in which no release of nitrogen oxides was observed by mass spectrometry.

The BET surface areas were determined by $\mathrm{N}_{2}$ physisorption. The specific surface areas of the catalyst samples calcined at $673 \mathrm{~K}$ were found to be in the range from 88 to $133 \mathrm{~m}^{2} \mathrm{~g}^{-1}$. The two ternary samples Co3Mn0 and CoOMn3 exhibit smaller surface areas than the quaternary samples. Especially, the Mn-free sample showed a significantly smaller BET surface indicating that $\mathrm{Mn}$ is an effective 
Table 1: Elemental composition and BET surface areas of the prepared quaternary catalyst samples. The ratio denoted in the sample refers to the molar ratio relative to the $\mathrm{Mg}$ content. The samples were produced by varying the concentration of the cobalt nitrate or manganese nitrate in the precursor solution. The calcination was performed at $673 \mathrm{~K}$ in air.

\begin{tabular}{lllllll}
\hline Sample & $\begin{array}{l}\mathrm{Co} \\
(\mathrm{wt} . \%)\end{array}$ & $\begin{array}{l}\mathrm{Mn} \\
(\mathrm{wt} . \%)\end{array}$ & $\begin{array}{l}\mathrm{Al} \\
(\mathrm{wt} \%)\end{array}$ & $\begin{array}{l}\mathrm{Mg} \\
(\mathrm{wt} \%)\end{array}$ & $\begin{array}{l}\mathrm{O}^{\mathrm{a}} \\
(\mathrm{wt} \%)\end{array}$ & $\begin{array}{l}\text { BET area } \\
\left(\mathrm{m}^{2} \mathrm{~g}^{-1}\right)\end{array}$ \\
\hline Co3Mn0 & 54.6 & 0 & 4.6 & 5.8 & 35.0 & 87.5 \\
Co3Mn1 & 44.4 & 12.4 & 3.6 & 4.7 & 34.9 & 133.2 \\
Co3Mn2 & 37.1 & 20.4 & 3.2 & 3.9 & 35.4 & 130.2 \\
Co3Mn3 & 32.0 & 26.4 & 3.2 & 3.6 & 34.8 & 125.8 \\
Co2Mn3 & 24.3 & 30.1 & 3.0 & 4.3 & 38.3 & 131.8 \\
Co1Mn3 & 15.9 & 38.2 & 3.7 & 5.2 & 37.0 & 122.5 \\
Co0Mn3 & 0 & 55.5 & 5.0 & 6.6 & 32.9 & 108.5 \\
\hline a calculated by assuming that the rest is oxygen, ie. $100 \%-\mathrm{Co} \%-\mathrm{Mn} \%-\mathrm{Al} \%-\mathrm{Mg} \%$
\end{tabular}

structural promoter. The presence of both $\mathrm{Co}$ and $\mathrm{Mn}$ led to BET areas in the range of $123-133 \mathrm{~m}^{2} \mathrm{~g}^{-1}$. However, a clear correlation between the BET area and the $\mathrm{Co}: \mathrm{Mn}$ ratio cannot be established. Following the IUPAC classification the isotherms of the samples can be assigned to type IV or $\mathrm{V}$ adsorption isotherms [31]. The hysteresis between the adsorption and desorption isotherms was clearly visible for all catalysts indicating the presence of mesopores with a narrow pore size distribution in the range between 4 to 8 nm (not shown).

XRD was used to study the bulk crystalline phases in the oxides. The XRD patterns of the catalyst samples (Fig. 1) reveal the presence of spinel-type structures as expected based on the chosen synthetic route [18]. The general formula of the spinel oxide structure is $\mathrm{A}^{\mathrm{II}} \mathrm{B}^{\mathrm{III}}{ }_{2} \mathrm{O}_{4}$, in which tetrahedral sites $\mathrm{A}^{\mathrm{II}}$ are occupied by $\mathrm{Mg}^{2+}, \mathrm{Co}^{2+}$ or $\mathrm{Mn}^{2+}$ cations, and octahedral sites $\mathrm{B}^{\mathrm{III}}$ by $\mathrm{Al}^{3+}, \mathrm{Co}^{3+}$ or $\mathrm{Mn}^{3+}$ cations. The structure can be derived from the pure $\mathrm{MgAl}_{2} \mathrm{O}_{4}$ spinel or the corresponding non-stoichiometric spinel solid solutions [32].

Samples Co3Mn0 and Co3Mn1 consist mainly of cubic spinel. As indicated by the narrow lines, the sample $\mathrm{Co} 3 \mathrm{Mn} 0$ had the highest degree of crystallinity, which is in agreement with its low BET surface area. In the diffraction patterns of samples Co3Mn2, Co3Mn3, Co2Mn3, and Co1Mn3 additional reflections of tetragonal spinel emerge. It is known that this structural change occurs when a higher amount of $\mathrm{Mn}$ is incorporated into the oxide structure [33]. In addition, a $\mathrm{CoMnO}_{3}$ phase of the rhombohedral ilmenitetype can be identified [34]. This rhombohedral phase is known to coexist with cubic and tetragonal Co-Mn oxides and may originate from the formation of $\mathrm{Mn}^{4+}$ cations during calcination $[21,25]$. The Co-free CoOMn3 catalyst probably consists of a tetragonal $\mathrm{MnMn}_{2} \mathrm{O}_{4}$ spinel with additional $\mathrm{Mg}^{2+}$ and $\mathrm{Al}^{3+}$ ions in the lattice.

Although the elemental compositions of all samples do not match fixed stoichiometries (Table 1), the identification of distinct phases is possible. The predominant phases of all samples can be described as oxides that consist of

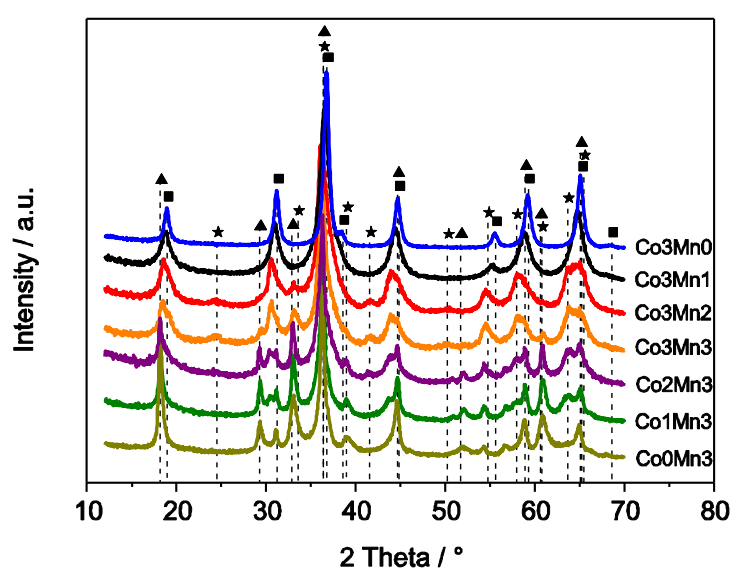

Fig. 1: X-ray diffraction patterns of the calcined catalysts. The positions of the reflections of cubic ( PDF 38-0814), tetragonal ( $\Delta$ PDF 72-1336) $\mathrm{AB}_{2} \mathrm{O}_{4}$ and rhombohedral (1PDF 12-0476) $\mathrm{ABO}_{3}$ phases are indicated by the symbols.

either a cubic solid solution, or a mixture of cubic and tetragonal solid solutions [35]. The tetragonal structure is stabilized by $\mathrm{Mn}^{3+}$ cations incorporated in the octahedral B sites. The $\mathrm{Mn}^{3+}$ cation is prone to produce a large JahnTeller distortion, as known from the spinel-type hausmannite $\mathrm{MnMn}_{2} \mathrm{O}_{4}$ [36]. The reflections that correspond to the tetragonal phase are shifted to smaller $2 \Theta$ angles with increasing Mn content. For instance, the (111) and (220) reflections at $2 \Theta=18.9$ and $44.6^{\circ}$ in the diffraction pattern of $\mathrm{Co} 3 \mathrm{Mn} 0$ in Fig. 1 are shifted in the pattern of Co3Mn3 to 18.2 and $43.9^{\circ}$, respectively, caused by the enlargement of the unit cell of the tetragonal solid solution. The line broadening obtained in all patterns is due to the small size of the crystalline bulk domains.

\subsection{Temperature-programmed reduction}

TPR experiments in diluted $\mathrm{H}_{2}$ were carried out in order to examine the reduction characteristics of the multicomponent oxide samples. The resulting TPR profiles are shown in Fig. 2. The reduction of $\mathrm{Mg}$ or $\mathrm{Al}$ oxides under the applied reduction conditions is highly unlikely, but the presence of these oxides has a strong impact on the reducibility of the Co cations and, correspondingly, on the TPR profiles. Compared to pure $\mathrm{Co}_{3} \mathrm{O}_{4}$, the reduction of Co ions in solid solutions with $\mathrm{MgO}$ is more difficult, as the $\mathrm{Co}$ and $\mathrm{Mg}$ ions can share oxygen anions in the lattice. Consequently, the strength of the metal-oxygen bond increases and the reduction peaks are shifted to higher temperatures [37]. A similar effect as described for $\mathrm{MgO}$ can be assumed for $\mathrm{Al}^{3+}$ ion in $\mathrm{Co}-\mathrm{Al}$ solid solutions. Arnoldy and Moulijn [38] suggested the concept of polarization of the Co-O bonds by $\mathrm{Al}^{3+}$ ions in the spinel structure: the $\mathrm{Al}^{3+}$ ions can shift the covalent character of the Co-O bond to a more ionic one, resulting also in an increase of the reduction temperature of the Co ions. It is reasonable to assume that 


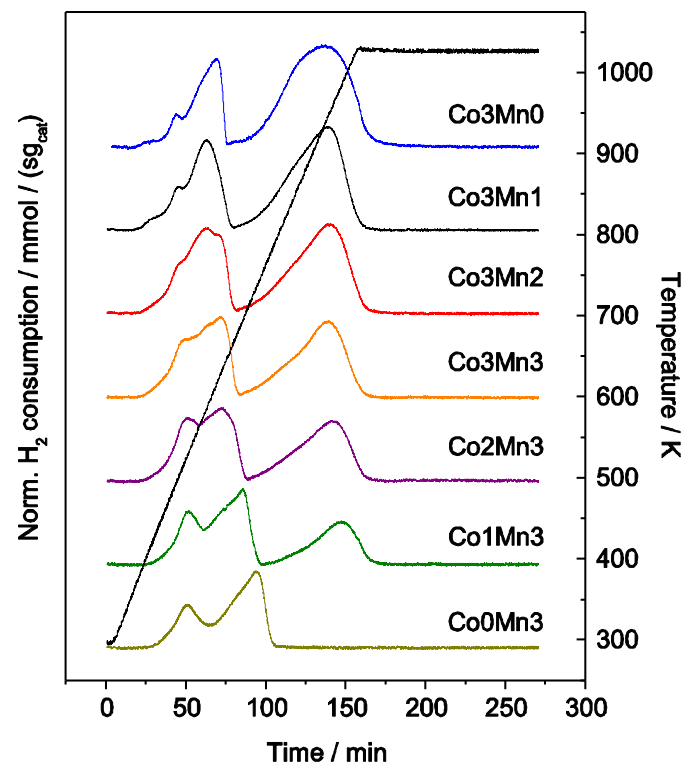

Fig. 2: $\mathrm{H}_{2}$ TPR profiles of the calcined catalyst samples. The temperature profile is given at the right ordinate.

in all the samples the $\mathrm{H}_{2}$ uptake originates from the reduction of $\mathrm{Co}$ and/or Mn oxides. Furthermore, it is known from TPR investigations on Mn oxides in literature that the reduction is limited to the formation of $\mathrm{Mn}^{2+}$ cations under the applied experimental conditions [20]. The formation of metallic $\mathrm{Mn}^{0}$ can be excluded below $1473 \mathrm{~K}$ when using $\mathrm{H}_{2}$ as reducing agent $[22,39]$.

The reduction of the Co-free sample CoOMn3 results in two peaks with $\mathrm{T}_{\max }=525 \mathrm{~K}$ and $735 \mathrm{~K}$ (Fig. 2). Integrating both peak areas disclosed that the molar $\mathrm{H}_{2}$ consumption corresponds to half of the molar amount of $\mathrm{Mn}$ in the sample suggesting the reduction of $\mathrm{Mn}^{3+}$ to $\mathrm{Mn}^{2+}$. The ratio between the $\mathrm{H}_{2}$ consumption during the first and second peak is roughly 1 to 2 . Assuming the presence of a $\mathrm{Mn}_{2} \mathrm{O}_{3}$ phase after calcination, the reduction from $\mathrm{Mn}_{2} \mathrm{O}_{3}$ to $\mathrm{MnMn}_{2} \mathrm{O}_{4}$ in the first step and further to $\mathrm{MnO}$ in the second step is in good agreement with the $\mathrm{H}_{2}$ consumption derived from the two TPR peaks. The XRD pattern of Co0Mn3 suggested the presence of a tetragonal spinel structure in the calcined sample. In case of $\mathrm{MnMn}_{2} \mathrm{O}_{4}$ the $\mathrm{Mn}^{\mathrm{II}}: \mathrm{Mn}^{\mathrm{III}}$ ratio would be stoichiometrically 1 to 2 . Therefore, the $\mathrm{MnMn}_{2} \mathrm{O}_{4}$ phase can be ruled out by the TPR results. The tetragonal spinel phase disclosed by XRD studies suggests the presence of $\gamma-\mathrm{Mn}_{2} \mathrm{O}_{3}$. This phase was described as a metastable defect spinel having the formula $\mathrm{Mn}_{2 / 3} \mathrm{Mn}_{2} \mathrm{O}_{4}$, where one-third of the tetrahedral sites are vacancies $[40,41]$. Sample Co0Mn3 also contains additional $\mathrm{Mg}^{2+}$ and $\mathrm{Al}^{3+}$ ions, which render the migration of $\mathrm{Mn}^{3+}$ ions to tetrahedral sites feasible and alter the reducibility of $\mathrm{Mn}$ compared to the TPR of the pure $\gamma-\mathrm{Mn}_{2} \mathrm{O}_{3}$ phase $[42,43]$. In addition, the presence of $\mathrm{MnO}_{2}$ can be excluded based on the observed shape of the TPR profile [43].

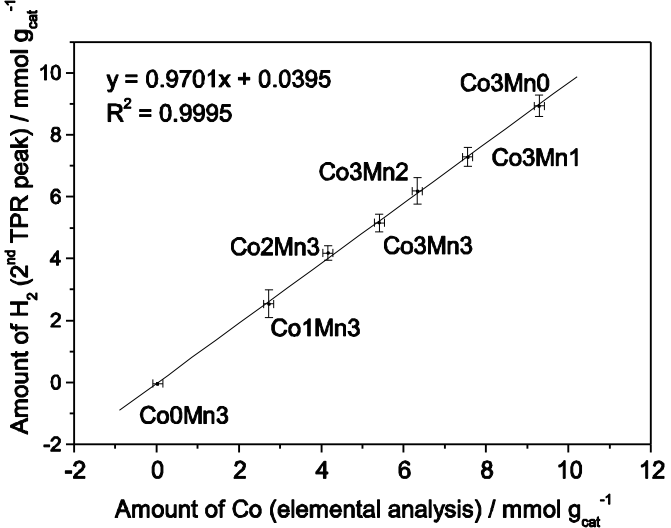

Fig. 3: Correlation between the molar amounts of consumed $\mathrm{H}_{2}$ of the second TPR peak and the molar Co amount determined by elemental analysis. The molar amount was referred to the sample mass of the TPR experiment. The equation of the linear fit curve and the correlation coefficient are indicated in the figure.

The first main peak of the Mn-free sample Co3Mn0 contains one shoulder at $490 \mathrm{~K}$ and a maximum at $610 \mathrm{~K}$. The $\mathrm{Co}^{2+} / \mathrm{Co}^{3+}$ stoichiometry in a spinel usually is 1 to 2 , thus the amount of $\mathrm{Co}^{3+}$ should be two-thirds of the total Co amount. The molar $\mathrm{H}_{2}$ consumption during the reduction peak below $600 \mathrm{~K}$ is half of the molar amount of $\mathrm{Co}^{3+}$ ions disclosing the reduction of $\mathrm{Co}^{3+}$ cations to $\mathrm{Co}^{2+}$. The occurrences of two stages in the first peak may originate from the reduction of $\mathrm{Co}^{3+}$ from either tetrahedral or octahedral sites.

The TPR profiles of all Co-Mn mixed samples can be divided in two stages: several overlapping maxima in the low-temperature peak, and one broad peak at higher temperatures. Up to five different reduction steps can occur in the low-temperature peak: the reduction of $\mathrm{Mn}^{4+}$ to $\mathrm{Mn}^{3+}$, the two step reduction of $\mathrm{Mn}_{2} \mathrm{O}_{3}$ to $\mathrm{MnMn}_{2} \mathrm{O}_{4}$ and further to $\mathrm{MnO}$, and the reduction of $\mathrm{Co}^{3+}$ to $\mathrm{Co}^{2+}$, which is also supposed to occur in two steps in analogy to the sample Co3Mn0. Due to the defective spinel found in sample $\mathrm{Co} 0 \mathrm{Mn} 3$ it can be concluded that the $\mathrm{Mn}$ oxides in all Co$\mathrm{Mn}$ mixed samples contain either trivalent $\mathrm{Mn}^{3+}$ cations in similar defect spinel structures or $\mathrm{Mn}^{4+}$ in the case of rhombohedral ilmenite (see Sec 3.1.). Accordingly, the presence of $\mathrm{Mn}^{2+}$ cations in the calcined catalysts can be excluded. The maximum or shoulder at around 625-725 K is shifted to lower temperature with increasing Co concentrations. This overall shift of the whole peak to lower temperatures with increasing Co concentration can be attributed to the presence of Co oxides that promote the reduction of $\mathrm{Mn}$ oxides as described for Co-Mn spinel mixed oxides [39]. Because this peak maximum emerges in all TPR profiles, it can be related likewise to the second reduction step of $\mathrm{Mn}$ spinel or $\mathrm{Co}$ spinel to $\mathrm{MnO}$ or $\mathrm{CoO}$, respectively. Nevertheless, the individual maxima or shoulders in the low temperature peak can hardly be distin 

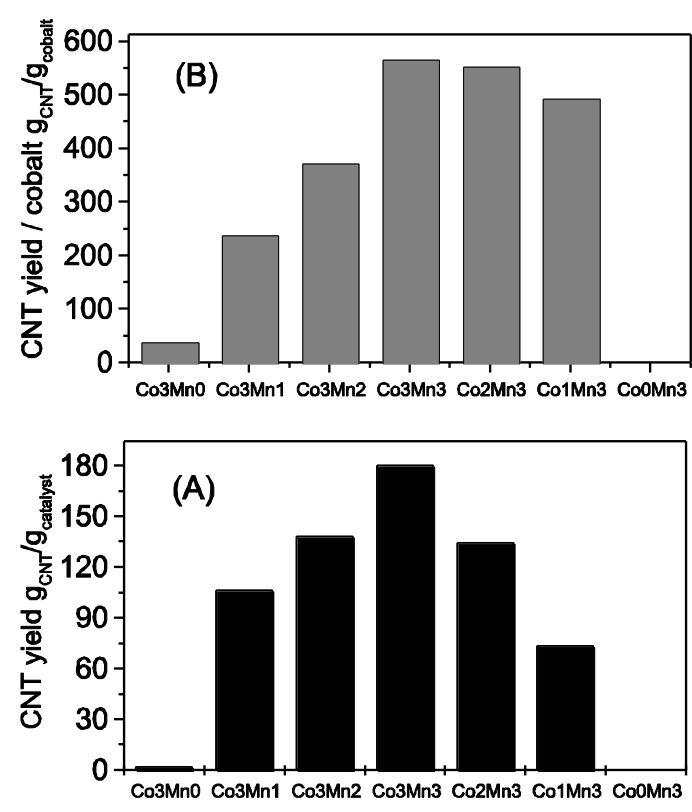

Fig. 4: The CNT yields related to the catalyst mass (A) and to the cobalt content (B) after $2 \mathrm{~h}$ in a feed gas consisting of $\mathrm{C}_{2} \mathrm{H}_{4}$ and $\mathrm{H}_{2}$.

guished. Therefore, a clear assignment to the reduction of a specific oxide is not possible.

In contrast to the low-temperature reduction process, the broad peak from $725-1025 \mathrm{~K}$ exclusively originates from the reduction of Co oxide as indicated by the comparison with the CoOMn3 sample. The peaks in this region are shifted to higher temperatures with increasing Mn content, which can be attributed to the retarding effect of $\mathrm{Mn}$ on the reduction kinetics of Co oxide [22]. The clear peak assignment of the TPR profile allows a quantitative analysis of the peaks. It is found that the molar $\mathrm{H}_{2}$ consumption in the high-temperature region is linearly correlated with the molar amount of Co (Fig. 3). The slope of the linear regression curve was found to be 0.97 , and the correlation coefficient amounted to $\mathrm{R}^{2}=0.9995$. It is reported that cobalt cations incorporated in oxide structures can be reduced by $\mathrm{H}_{2}$ to the metallic state $[20,39]$. For the reduction of $\mathrm{Co}^{2+}$ to $\mathrm{Co}^{0}$ the stoichiometry between $\mathrm{Co}$ and $\mathrm{H}_{2}$ is $1: 1$, which corresponds exactly to the observed ratio in the TPR studies. Hence, the broad reduction peaks at high temperature can be undoubtedly attributed to the reduction of $\mathrm{Co}^{2+}$ ions to metallic $\mathrm{Co}$, which is the only component in the quaternary Co-Mn-Al-Mg system that is reduced to the metallic state under the applied conditions.

\subsection{CNT synthesis}

For the growth of CNTs, the catalysts were first heated from room temperature to $923 \mathrm{~K}$ in a mixture of $\mathrm{H}_{2}$ and $\mathrm{He}$ as reductive pretreatment. $\mathrm{H}_{2}$ was also a feed gas component during the growth at $923 \mathrm{~K}$ to maintain the activity of the Co catalysts. The yields of all samples are shown in Fig. 4 (A). For sample Co3Mn0 only a very low $\mathrm{CNT}$ yield of $2.1 \mathrm{~g}_{\mathrm{CNT}} / \mathrm{g}_{\mathrm{cat}}$ was obtained. The yield was significantly increased by a factor of 50 when using the Co3Mn1 catalyst. The catalytic activity was further enhanced for Co3Mn2. An extraordinarily high yield of 179.9 $\mathrm{g}_{\mathrm{CNT}} / \mathrm{g}_{\text {cat }}$ was obtained with the Co3Mn3 sample, which is 84 times higher than the yield of the Mn-free Co3Mn0 catalyst. A further increase of the Mn concentration led to a decrease of the yield. The CoOMn3 sample without Co was completely inactive, indicating that $\mathrm{Co}$ is the active species for the CNT synthesis. The intrinsic yield normalized to the Co mass of the applied sample is shown in Fig. 4 (B). Here, also the Co3Mn3 sample was found to be the most active catalyst. However, the intrinsic yield revealed that the Mnrich samples Co2Mn3 and Co1Mn3 have similar activities compared to sample Co3Mn3 .

\subsection{Electron microscopy}

TEM was applied to investigate the morphology of the CNTs synthesized by CCVD over the catalysts Co3Mn1, Co3Mn3 and Co1Mn3. It was found that the samples consisted exclusively of agglomerates of multiwalled CNTs, and other types of carbon were not observed (Fig. 5). Due to the exceptionally high yield, the catalysts are highly dispersed in the CNT products. Therefore, the residual catalysts cannot be found in the CNT agglomerates. It can be seen from the TEM images that the CNTs are characterized by parallel walls in general. Cup-like structures, i.e. inner walls, can also be observed inside the CNTs that divide the inner void into closed volumes. Additionally, asymmetric CNTs with different numbers of walls were observed, indicating rather defective structures. The asymmetry in the number of walls may be caused by fragments of the Mn-Mg-Al oxide matrix attached to the surface of the active $\mathrm{Co}^{0}$ nanoparticles found by TEM [27].

The homogeneity of the CNTs grown from different catalysts was investigated by measuring the diameter of at least 330 CNTs using SEM. The obtained diameter distributions are shown in Fig. 6. It was found by TEM that the number of walls varied with the catalyst compositions. The mean outer diameter as well as the standard deviation increased with the Co concentration in the catalysts. A rather narrow distribution of the outer diameter was observed for the Co1Mn3 catalyst. About $95 \%$ of the CNTs were in the range between 4 and $15 \mathrm{~nm}$ with a maximum from 8 to 9 $\mathrm{nm}$. Only very few tubes were found with diameters greater than $15 \mathrm{~nm}$. The mean diameter of the CNTs produced from Co3Mn3 catalyst was shifted to 10 to $11 \mathrm{~nm}$. The distribution was broader than that of Co1Mn3, and the fraction of CNTs with diameters smaller then $16 \mathrm{~nm}$ was remarkably decreased to $80 \%$. The CNTs grown from the Co3Mn1 catalyst exhibited an even broader distribution and a higher standard deviation, where only $71 \%$ of all CNTs were within the range of 4 to $15 \mathrm{~nm}$. 

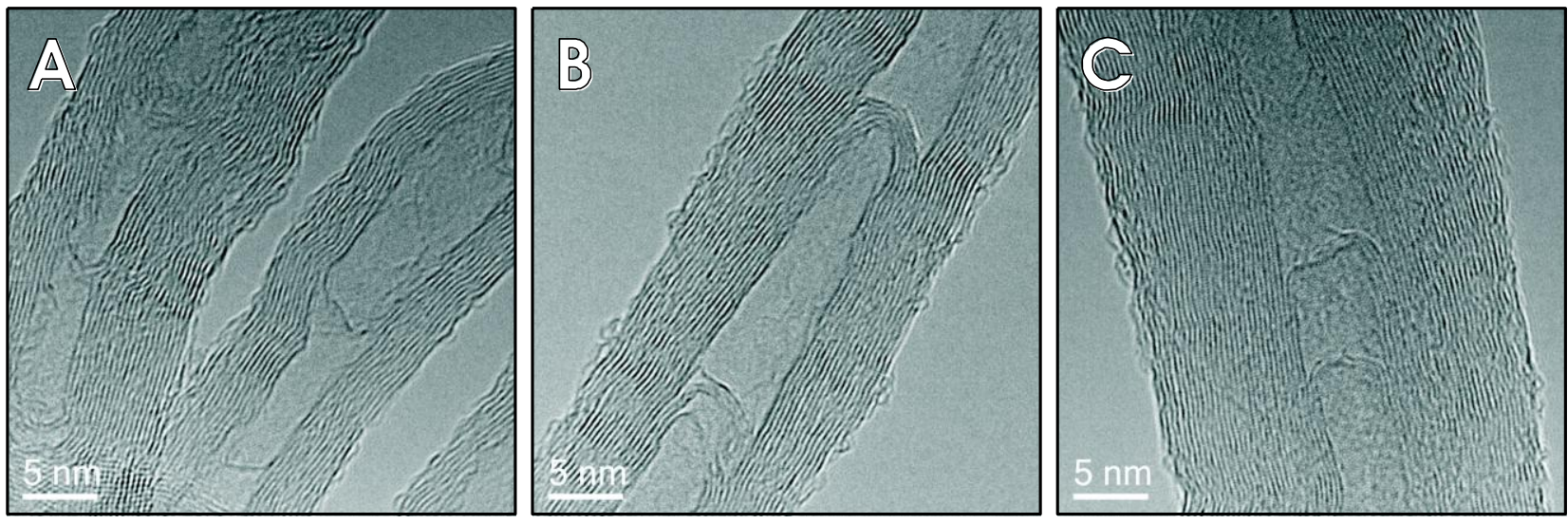

Fig. 5: TEM images of CNTs obtained from ethene by CCVD over the catalysts Co1Mn3 (A), Co3Mn3 (B) and Co3Mn1(C).

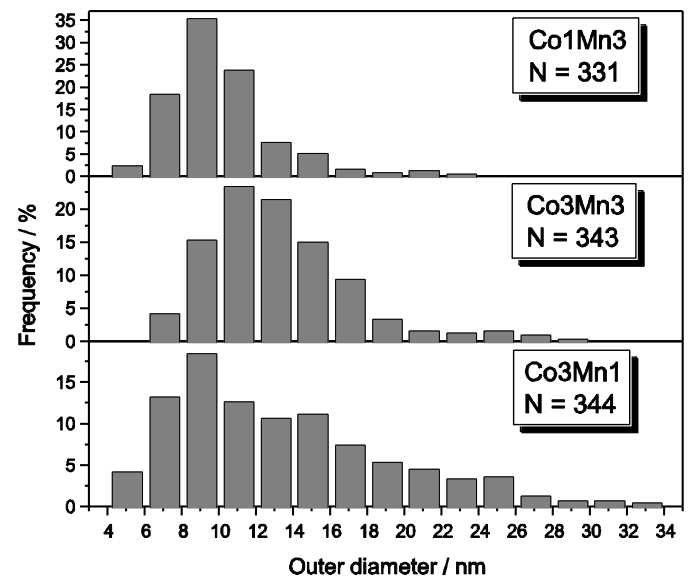

Fig. 6: Size distributions of the outer CNT diameter of samples Co1Mn3, Co3Mn3, and Co3Mn1 determined by SEM. The total numbers $\mathrm{N}$ of counted CNTs are indicated.

It is generally accepted that the CNT diameter depends on the catalyst particle size, especially in the case of the tip growth $[44,45]$. Therefore, the evolution of the mean CNT diameter can be used to evaluate the influence of the Mn content on the size of the Co nanoparticles in the active state. The high amount of $\mathrm{Mn}$ in the Co1Mn3 catalysts favored the nucleation of smaller Co particles with a very narrow size distribution, whereas the low Mn content in the Co3Mn1 system leads to larger Co particles with a broader size distribution.

\subsection{Raman spectroscopy}

Raman spectroscopy is known to be sensitive to the structure of carbon materials [46,47].

Fig. 7 displays the first-order Raman spectra of the obtained CNT samples. For comparison, the intensity of the spectra was normalized to the most intense band at 1324

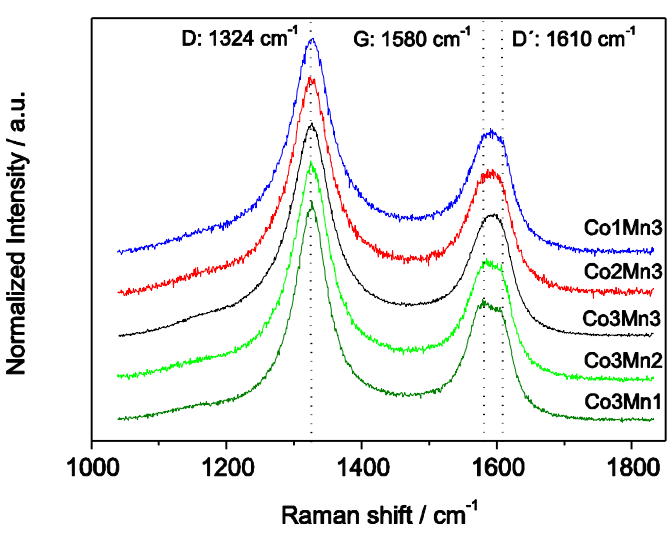

Fig. 7: First-order Raman spectra of CNTs obtained from ethene by CCVD over catalyst samples Co1Mn3, Co2Mn3 Co3Mn3, Co3Mn2, and Co3Mn1.

$\mathrm{cm}^{-1}$. The amount of CNTs obtained from Co3Mn0 was very small, and no CNTs were obtained from Co0Mn3. Therefore, these two samples were excluded from Raman and TG-MS studies. All spectra exhibit two intense bands at $1324 \mathrm{~cm}^{-1}$ and $1590 \mathrm{~cm}^{-1}$. The G-band at $1590 \mathrm{~cm}^{-1}$ is characteristic for graphitic layers and corresponds to tangential $E_{2 g}$ in-plane vibrations $[48,49]$. Due to the presence of lattice defects and the loss of the long range in-plane symmetry, microcrystalline graphite shows intensive bands around 1350 and $1620 \mathrm{~cm}^{-1}$, i.e., the D- and D'-bands respectively. As it can be seen from Fig. 7 the G-band and the D'-band are broad and completely overlapping each other. For this reason, it was necessary to apply a spectral analysis to all the spectra. The intensities of the three bands were determined graphically using the spectral fitting method developed by Sadezky et al. [29]. This method allows a clear discrimination between the G-band and the $\mathrm{D}^{\prime}$-band. The ratio of the D- and G-bands $\left(\mathrm{I}_{\mathrm{D}} / \mathrm{I}_{\mathrm{G}}\right)$ is considered as an indicator to the structural order of CNTs $[47,50]$. It can be seen from Fig. 7 that in all the samples the D-bands are 
Table2: Intensity ratios of D- and G-bands in the Raman spectra of CNTs made from different catalysts.

\begin{tabular}{llllll}
\hline $\begin{array}{l}\text { CNTs from } \\
\text { catalyst }\end{array}$ & Co3Mn1 & Co3Mn2 & Co3Mn3 & Co2Mn3 & Co1Mn3 \\
\hline Intensity & & & & & \\
ratio D/G & 2.08 & 2.24 & 2.37 & 2.39 & 2.40 \\
\hline
\end{tabular}

rather intense compared to the G-bands. Quantitative analysis found that the $\mathrm{I}_{\mathrm{D}} / \mathrm{I}_{\mathrm{G}}$ ratios of the CNT samples vary in a narrow range from 2.08 to 2.40 (Table 2) indicating that the surface structures of these samples are very similar. Detailed examination disclosed that the $\mathrm{I}_{\mathrm{D}} / \mathrm{I}_{\mathrm{G}}$ ratio increased with increasing Mn content in the used catalyst, and in the TEM investigation that the CNT diameter decreases with increasing Mn content in the catalysts. Therefore, it can be concluded that the slight variation of the $\mathrm{I}_{\mathrm{D}} / \mathrm{I}_{\mathrm{G}}$ ratio is correlated with the CNT diameters, that is, smaller CNTs are somewhat more defective on the surface obviously due to the increase of curvature.

\subsection{TG-MS studies}

As disclosed by the TEM studies, the different catalysts resulted in CNTs with different dimensions, which should have different bulk and surface properties. TG-MS is known to be a sensitive technique for the characterization of the structure and the purity of CNTs [51].

Hence, thermogravimetry coupled with online mass spectrometry (TG-MS) was employed to study the thermal stability towards oxidative conditions of the CNTs grown from different catalysts. The residual catalyst particles in the CNTs can strongly influence the oxidation kinetics [52]. For this reason, the CNTs were investigated by TGMS as-prepared and after washing them thoroughly in $\mathrm{HNO}_{3}$ in order to remove the catalyst particles.

The CNTs were almost completely converted to $\mathrm{CO}_{2}$ in synthetic air as monitored by online MS. The onset temperature of the combustion of the as-prepared CNTs increased with increasing $\mathrm{Mn}$ and decreasing Co content in the applied catalysts (Fig. 8). The lowest oxidation stability was found for the CNTs obtained from sample Co3Mn1. The Mn-rich sample Co1Mn3 exhibited the highest oxidation resistance. The temperatures of $50 \%$ sample burn-off ranged from $769 \mathrm{~K}$ to $822 \mathrm{~K}$ and follow the same trend like the onset temperatures (Fig. 8), that is, all profiles of the mass loss curves exhibit a similar shape, and the differential TG (DTG) curves of all CNT samples have only one maximum (not shown). The full widths at half maximum of all DTG curves were about $80 \mathrm{~K}$. It is highly likely that the oxidation of CNTs from different catalysts follows the same reaction kinetics, as indicated by the similar shapes of the TG weight loss curves, which are just slightly shifted with respect to temperature. The single maximum found in the DTG profile also confirms that the carbon material consists exclusively of pure multiwalled CNTs.

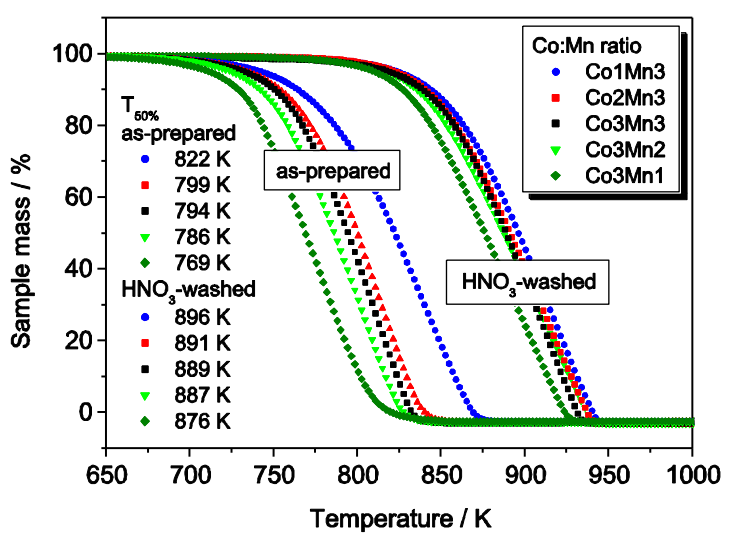

Fig. 8: TG mass loss curves of the as-prepared and the $\mathrm{HNO}_{3}$ washed CNTs during temperature-programmed combustion in synthetic air. The CNTs were synthesized from ethene by CCVD over catalyst samples Co1Mn3, Co2Mn3 Co3Mn3, Co3Mn2, and Co3Mn1. Additionally, the temperatures of $50 \%$ of the initial sample mass $\left(\mathrm{T}_{50 \%}\right)$ are listed.

In addition, it was found that the residual cobalt or cobalt oxides decreased the oxidation resistance of CNTs in agreement with literature results [52]. After washing all samples with nitric acid the oxidation resistance of the CNTs was significantly increased by $74-107 \mathrm{~K}$. The washing step cannot remove all the residual catalyst particles, especially not those encapsulated in CNTs. However, the rest of the residual catalyst particles should have no effect on the initial burn-off temperatures, because the particles, which were not removed during the washing step, remain initially encapsulated within the tubes and should not be active until reaching a high degree of combustion [53]. It can be seen from the TG weight loss curves in Fig. 8 that all washed samples were stable in air up to $800 \mathrm{~K}$, and the difference of the burn-off temperatures is in the narrow range of $20 \mathrm{~K}$, which points to a rather similar reactivity of the CNTs after washing.

The oxidation stability is assumed to be related to the degree of crystallinity of the CNTs [54], and it is also attributed to the presence of defects at the ends of the nanotubes $[53,55]$. Generally, higher oxidation stability suggest higher structural order and a lower number of defects, such as edges, vacancies, kinks and steps. The CNTs originating from the Mn-rich sample Co1Mn3 exhibit the highest oxidation stability and should therefore have the lowest defect concentration of all CNT samples. The oxidative stability of the CNTs depends directly on the edges of the graphite planes that are exposed to the gas phase, since TEM reveal the ends of the tubes to be open. These edge defects can be considered as highly reactive ring-shaped areas that will be oxidized at much lower temperatures than the surface of the basal planes. As the investigations by TEM revealed that the CNTs originating from sample Co3Mn1 have the broadest diameter distribution, the total area of these edge defects should be significantly increased. Consequently, the 


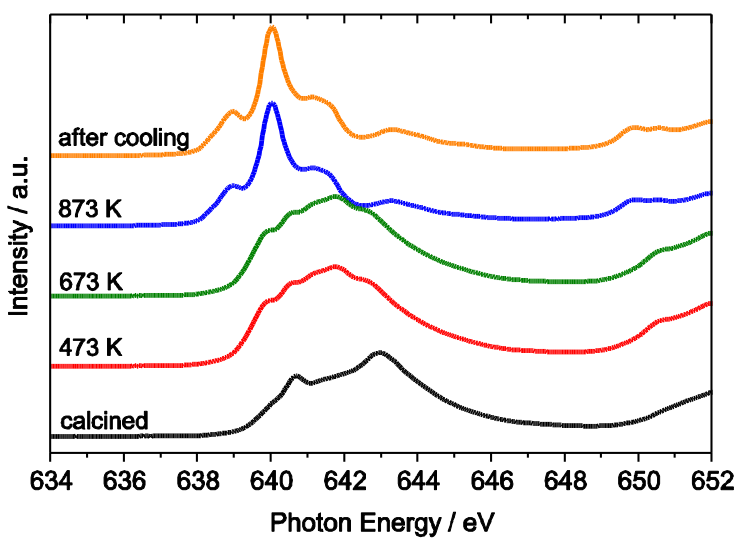

Fig. 9: Total electron yield Mn L-edge NEXAFS spectra of the calcined, step-wise $\mathrm{H}_{2}$ reduced and of the cooled sample after $\mathrm{C}_{2} \mathrm{H}_{4}$ exposure.

CNTs originating from sample Co3Mn1 exhibit the lowest stability towards oxidative conditions.

\subsection{NEXAFS at the Mn L-edge}

The near-edge X-ray analysis of fine structure spectroscopy (NEXAFS) of the sharp L-edge is a sensitive probe for the surface-near region and can resolve different oxidation states of mixed valent ions [56,57]. The state of the $\mathrm{Mn}$ ions during reduction and after growth reaction were investigated in order to provide information on the chemical state and the electronic structure of the Mn. Fig. 9 shows the NEXAFS of the Co3Mn3 sample after calcination, reduction at $473 \mathrm{~K}, 673 \mathrm{~K}$ and $873 \mathrm{~K}$ as well as the cooled sample after carbon deposition. The spectra of the Mn L-edge vary in shape and position with temperature indicating that the calcined sample underwent severe structural changes during the reduction in $\mathrm{H}_{2}$.

Starting from higher oxidation states the spectra obtained for the samples after reduction at $873 \mathrm{~K}$ and after reaction showed a sharp peak at $640 \mathrm{eV}$ with some satellites that can be attributed to the $\mathrm{Mn}^{2+}$ state [58]. Both spectra exposed very similar features compared to spectra of $\mathrm{MnO}$ reported in literature $[59,60]$ as well as to homovalent standards like $\mathrm{MnSO}_{4}$ and $\mathrm{MnCl}_{2}$ [61,62] demonstrating that the $\mathrm{Mn}$ ions in the surface near region are predominantly present as $\mathrm{Mn}^{2+}$. The observation that the spectrum does not undergo further changes between reduction and cooling indicates that $\mathrm{Mn}$ is present as $\mathrm{MnO}$ in the working catalyst. This homovalent species is assumed to improve the catalytic performance of the Co nanoparticles by strong metal-oxide interactions.

\subsection{Variation of the calcination temperature}

The properties of the active Co nanoparticles and the quality of the obtained CNTs are strongly related to the

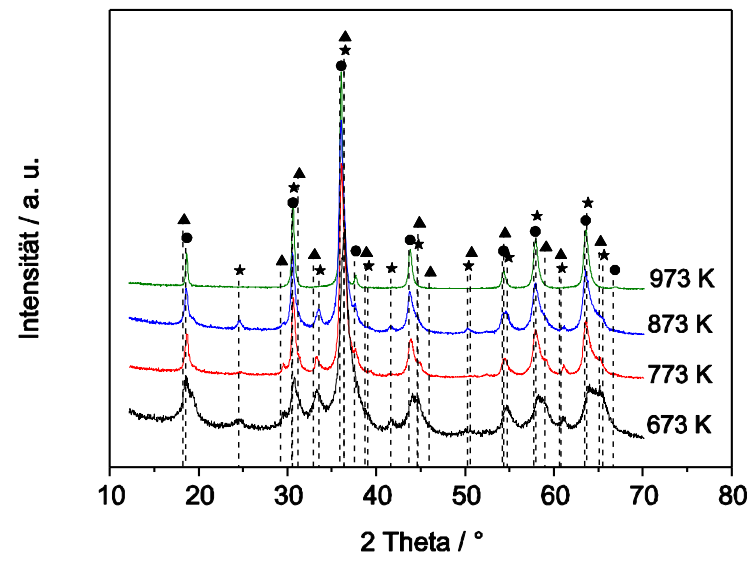

Fig. 10: X-ray diffraction patterns of catalyst Co3Mn3 samples calcined at $673 \mathrm{~K}, 773 \mathrm{~K}, 873 \mathrm{~K}$ and $973 \mathrm{~K}$. The positions of the reflections of cubic $\mathrm{AB}_{2} \mathrm{O}_{4}\left(\bullet \mathrm{PDF}\right.$ 84-0482), tetragonal $\mathrm{AB}_{2} \mathrm{O}_{4}$ ( $\triangle$ PDF 18-0408), and rhombohedral $\mathrm{ABO}_{3}$ ((PDF 12-0476) phases are indicated by the symbols.

degree of crystallinity of the initial oxide precursor, as recently reported for perovskite bulk catalysts [63]. In order to investigate the effect of the catalyst crystallinity, the calcination temperature of the most active Co3Mn3 sample was increased in steps of $100 \mathrm{~K}$. The position of the diffraction peaks of the rhombohedral phase did not shift with increasing calcination temperature and the intensity of the tetragonal phase decreased with higher temperatures (Fig. 10). Concerning cobalt manganese spinel-type oxides Vila et al. [33] described the reaction of the tetragonal and the cubic phases between $773 \mathrm{~K}$ and $973 \mathrm{~K}$ to form a new cubic phase, which was not present in the samples calcined at $673 \mathrm{~K}$. When this high temperature phase is cooled to room temperature, it decomposes again into the tetragonal and the new cubic phase, in which the manganese content of the cubic phase is increased [33]. A similar redistribution of the cations occurs in the samples calcined between 773 and $973 \mathrm{~K}$. This increase of the $\mathrm{Mn}^{3+}$ content at the Jahn-Tellerdistorted octahedral B sites results in a larger unit cell parameter although the lattices remains cubic, which is indicated by the slight shift of the line positions to smaller $2 \Theta$ angles observed by XRD. Additionally, the reflections of the spinel phase became narrower with increasing temperature, which can be attributed to the formation of larger crystallites. The XRD pattern of the sample calcined at 973 $\mathrm{K}$ showed exclusively the cubic spinel phase with very narrow reflection lines. This is also in agreement with the observations for $\mathrm{Co}_{1.2} \mathrm{Mn}_{1.8} \mathrm{O}_{4}$ from Vila et al. [33], who reported that the tetragonal spinel phase disappears at temperatures above $993 \mathrm{~K}$. Since this sample had a very low CNT yield, the low activity can be assigned to the lack of the tetragonal structure after the high temperature calcination.

The TPR patterns of the Co3Mn3 samples calcined at $773 \mathrm{~K}$ and $873 \mathrm{~K}$ are shown in Fig 11, and the sample calcined at $673 \mathrm{~K}$ is included for comparison. The profiles of the samples calcined at $773 \mathrm{~K}$ and $873 \mathrm{~K}$ have a very simi 


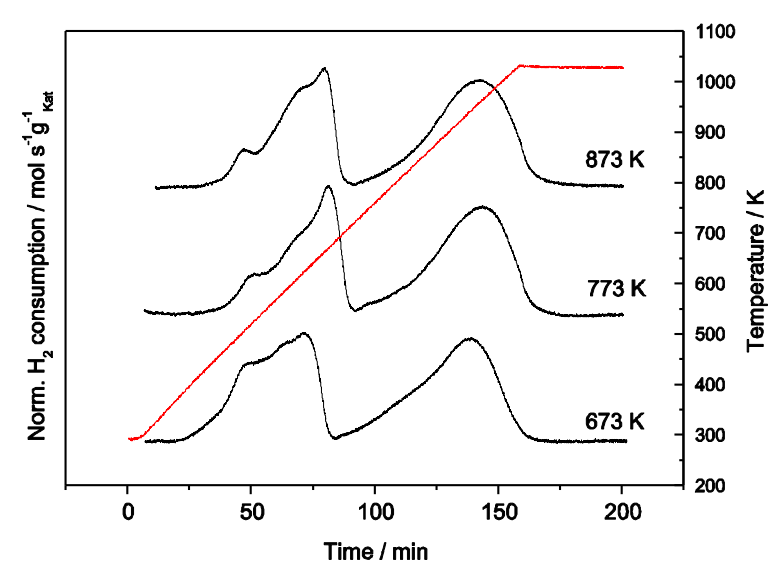

Fig. 11: $\mathrm{H}_{2}$ TPR profiles of sample Co3Mn3 calcined at $673 \mathrm{~K}$, $773 \mathrm{~K}$ and $873 \mathrm{~K}$.

Table3: Yields and BET areas of CNTs obtained with the Co3Mn3 catalyst as a function of the calcination temperature.

\begin{tabular}{lll}
\hline calcination temperature / $\mathrm{K}$ & yield $/ \mathrm{g}_{\mathrm{CNT}} / \mathrm{g}_{\text {cat }}$ & BET area of CNTs $/ \mathrm{m}^{2} \mathrm{~g}^{-1}$ \\
\hline 673 & 179.9 & 165.0 \\
773 & 212.7 & 145.4 \\
873 & 248.6 & 145.6 \\
973 & 29.8 & 165.1 \\
\hline
\end{tabular}

lar shape, and the peak maxima are found at almost the same positions. In agreement with the TPR results shown in Fig 2, both profiles can be divided into a low-temperature stage including several overlapping reduction steps and into one broad peak above $673 \mathrm{~K}$. The amount of $\mathrm{H}_{2}$ consumed at temperatures above $673 \mathrm{~K}$ is in agreement with the molar Co amount of the samples indicating again the formation of metallic $\mathrm{Co}^{0}$ nanoparticles. Compared to the sample calcined at $673 \mathrm{~K}$, all peaks are shifted to higher reduction temperatures pointing to the formation of larger crystallites during the calcination at higher temperatures, which is in agreement with the $\mathrm{XRD}$ results. In addition, the intensity of the shoulder at $485-560 \mathrm{~K}$ decreased in both patterns.

The variation of the calcination temperature had a very strong impact on the CNT yield. The increase from 673 to $773 \mathrm{~K}$ led to an increase of the CNT yield from 179.9 to $212.7 \mathrm{~g}_{\mathrm{CNT}} / \mathrm{g}_{\text {cat }}$, and further to $248.6 \mathrm{~g}_{\mathrm{CNT}} / \mathrm{g}_{\text {cat }}$ for the catalyst calcined at $873 \mathrm{~K}$ (Table 3 ). The yield was drastically decreased to $29.8 \mathrm{~g} / \mathrm{g}_{\text {cat }}$, when the dried catalyst precursor was calcined at $973 \mathrm{~K}$. The obtained CNTs from both catalysts calcined at $773 \mathrm{~K}$ and $873 \mathrm{~K}$ exhibited lower surface areas than that of the sample calcined $673 \mathrm{~K}$ (Table 3 ), which is in agreement with the broader size distributions found by TEM. The histogram in Fig. 12 shows the CNT outer diameter distribution originating from the Co3Mn3 sample calcined at $873 \mathrm{~K}$. The distribution ranges mainly from 5 to $26 \mathrm{~nm}$ having a maximum between $12-13 \mathrm{~nm}$. Only very few tubes with diameter above $26 \mathrm{~nm}$ were observed. Obviously, the diameter distribution is much broader as compared to the sample calcined at $673 \mathrm{~K}$. The

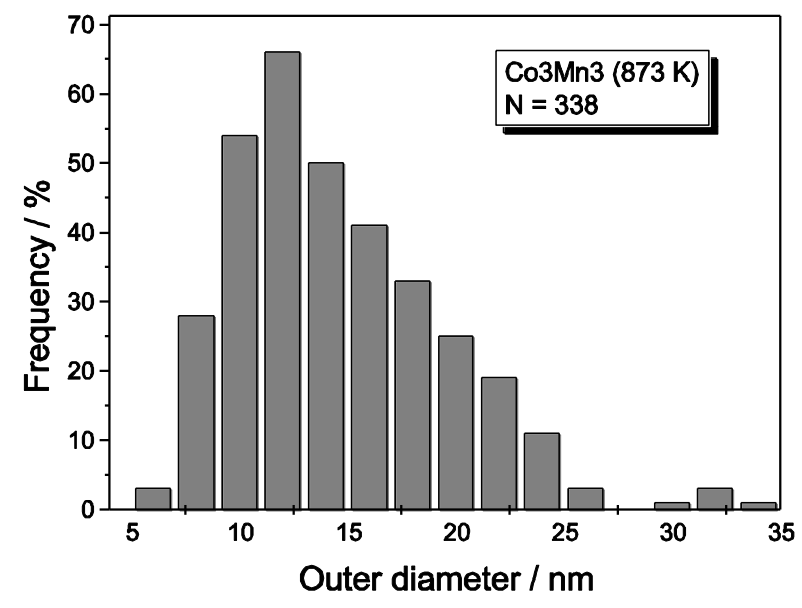

Fig. 12: Size distribution of the outer CNT diameters obtained with the catalyst Co3Mn3 calcined at $873 \mathrm{~K}$ determined by SEM. The total number of counted CNTs was $\mathrm{N}=338$.

CNT diameter as well as the CNT length and number can contribute to the higher yield obtained with the catalyst calcined at $873 \mathrm{~K}$. It is remarkable that no correlation was found between the catalytic activity and the size of the Co nanoparticles that influence the CNT diameters. This observation suggests that the presence of $\mathrm{MnO}$ may retard the deactivation of the $\mathrm{Co}^{0}$ nanoparticles due to coking. Further time-resolved studies on the CNT growth kinetics over the catalysts presented here are in progress to elucidate the growth and deactivation mechanisms in detail.

\section{Conclusions}

Quaternary Co-Mn-Al-Mg oxide catalysts were synthesized by the precipitation of nitrate salts with $\mathrm{NaOH}$ and subsequent calcination. The $\mathrm{Co}: \mathrm{Mn}$ ratio was varied to investigate the strong promoting effect of $\mathrm{Mn}$. The obtained mixed oxides were found to have mainly spinel-type structures after calcination. During reduction in $\mathrm{H}_{2}$ the spinel structure collapsed and formed a Co-Mn-Al-Mg oxide matrix, from which the metallic Co nanoparticles segregated at temperatures above $700 \mathrm{~K}$. An increase of the Mn content in the mixed oxides changed the redox properties of $\mathrm{Co}$ and led to an increased reduction temperature. It was found that the activity for CNT growth strongly depends on the Mn content of the catalysts having a maximum CNT yield at a $\mathrm{Co}: \mathrm{Mn}$ ratio of 1:1. A higher Mn content results in a narrower CNT diameter size distribution.

The extent of Mn addition to the Co catalyst did not affect the remarkably high selectivity of the catalyst towards multiwalled CNTs and the homogeneity in diameter and structure of the resulting CNTs, which had rather similar properties in the Raman and TG investigations. The CNT yield was further increased by increasing the calcination temperature of the dried catalyst precursor resulting in a higher degree of crystallinity of the spinel oxide. 
The high activity and selectivity of the catalyst may be attributed to strong interactions between the $\mathrm{Co}^{0}$ nanoparticles and the Mn-Al-Mg oxide matrix. Investigations on the surface near region confirm the presence monovalent $\mathrm{Mn}$ (II) oxide in the working catalyst.

The close contact between $\mathrm{MnO}$ and the $\mathrm{Co}^{0}$ nanoparticles is assumed to decrease the tendency to generate amorphous carbon thus slowing down the deactivation by encapsulation of the $\mathrm{Co}^{0}$ nanoparticles.

\section{References}

[1] Andrews R, Jacques D, Qian D, Rantell T. Multiwall carbon nanotubes: synthesis and application. Acc Chem Res 2002;35(12):1008-17.

[2] Bitter JH. Nanostructured carbons in catalysis a janus material-industrial applicability and fundamental insights. J Mater Chem 2010;20:7312-21.

[3] Nessim GD. Properties, synthesis, and growth mechanisms of carbon nanotubes with special focus on thermal chemical vapor deposition. Nanoscale 2010;2:1306-23.

[4] Serp P, Corrias M, Kalck P. Carbon nanotubes and nanofibers in catalysis. Appl Catal A: General 2003;253(2):337-58.

[5] See CH, Harris AT. A review of carbon nanotube synthesis via fluidized-bed chemical vapor deposition. Ind Eng Chem Res 2007;46(4):997-1012.

[6] Robertson J. Realistic applications of CNTs. Materials Today 2004;7(10):46-52.

[7] Harris A, See C, Liu J, Dunens O, Mackenzie K. Towards the large-scale synthesis of carbon nanotubes in fluidised beds. J Nanosci Nanotechnol 2008;8:2450-7.

[8] Jose-Yacaman M, Miki-Yoshida M, Rendon L, Santiesteban JG. Catalytic growth of carbon microtubules with fullerene structure. Appl Phys Lett 1993;62(6):657-9.

[9] Louis B, Gulino G, Vieira R, Amadou J, Dintzer T, Galvagno S, Centi G, Ledoux M, Pham-Huu C. High yield synthesis of multi-walled carbon nanotubes by catalytic decomposition of ethane over iron supported on alumina catalyst. Catal Today 2005;102-103:23-8.

[10] Bajwa N, Li X, Ajayan PM, Vajtai R. Mechanisms for catalytic cvd growth of multiwalled carbon nanotubes. J Nanosci Nanotechnol 2008;8:6054-64.

[11] Esconjauregui S, Whelan CM, Maex K. The reasons why metals catalyze the nucleation and growth of carbon nanotubes and other carbon nanomorphologies. Carbon 2009;47(3):659-69.

[12] Balogh Z, Halasi G, Korbély B, Hernadi K. Cvd-synthesis of multiwall carbon nanotubes over potassium-doped supported catalysts. Appl Catal A: General 2008;344(12):191-7.

[13] Lee CJ, Park JH, Park J. Synthesis of bamboo-shaped multiwalled carbon nanotubes using thermal chemical vapor deposition. Chem Phys Lett 2000;323(5-6):560-5.

[14] Piedigrosso P, Konya Z, Colomer JF, Fonseca A, Van Tendeloo G, Nagy J. Production of differently shaped multi-wall carbon nanotubes using various cobalt supported catalysts. Phys Chem Chem Phys 2000;2:163-70.

[15] See $\mathrm{CH}$, Harris AT. $\mathrm{CaCO}_{3}$ supported Co-Fe catalysts for carbon nanotube synthesis in fluidized bed reactors. AIChE J 2008;54:657-63.

[16] Shlyakhova EV, Yudanov NF, Okotrub AV, Shubin YV, Yudanova LI, Bulusheva LG. Growth of carbon nano-

\section{Acknowledgments}

Financial support by the German Federal Ministry of Education and Research (BMBF) through the CarboScale project (grants $03 \mathrm{X} 0040 \mathrm{H}$ and $03 \mathrm{X0040G)}$ within the scope of the Inno.CNT alliance is gratefully acknowledged.

tubes via chemical vapor deposition on Co catalyst nanoparticles dispersed in $\mathrm{CaO}$. Inorg Mater 2008;44:213-8.

[17] Xia W, Jin C, Kundu S, Muhler M. A highly efficient gasphase route for the oxygen functionalization of carbon nanotubes based on nitric acid vapor. Carbon 2009;47(3):919-22.

[18] Bierdel M, Buchholz S, Michele V, Mleczko L, Rudolf R, Voetz M, Wolf A. Industrial production of multiwalled carbon nanotubes. Physica Status Solidi (b) 2007;244(11):3939-43.

[19] Govindaraj A, Flahaut E, Laurent C, Peigney A, Rousset A, Rao CNR. An investigation of carbon nanotubes obtained from the decomposition of methane over reduced $\mathrm{Mg}_{1-\mathrm{x}} \mathrm{M}_{\mathrm{x}} \mathrm{Al}_{2} \mathrm{O}_{4}$ spinel catalysts. $\mathrm{J}$ Mater Res 1999;14:2567-76.

[20] Guse K, Papp H. Xps characterization of the reduction and synthesis behaviour of $\mathrm{Co} / \mathrm{Mn}$ oxide catalysts for fischer-tropsch synthesis. Fresenius J Anal Chem 1993;346:84-91.

[21] Mirzaei AA, Faizi M, Habibpour R. Effect of preparation conditions on the catalytic performance of cobalt manganese oxide catalysts for conversion of synthesis gas to light olefins. Appl Catal A: General 2006;306:98-107.

[22] Morales F, Grandjean D, Mens A, de Groot FMF, Weckhuysen BM. X-ray absorption spectroscopy of $\mathrm{Mn} / \mathrm{Co} / \mathrm{Tio}_{2}$ fischer-tropsch catalysts: Relationships between preparation method, molecular structure, and catalyst performance. J Phys Chem B 2006;110(17):8626-39.

[23] Obalová L, Jirátová K, Kovanda F, Pacultová K, Lacný Z, Mikulová Z. Catalytic decomposition of nitrous oxide over catalysts prepared from $\mathrm{Co} / \mathrm{Mg}-\mathrm{Mn} / \mathrm{Al}$ hydrotalcitelike compounds. Appl Catal B: Environmental 2005;60(34):289-97.

[24] Obalová L, Pacultová K, Balabánová J, Jirátová K, Bastl Z, Valásková M, Lacný Z, Kovanda F. Effect of Mn/Al ratio in Co-Mn-Al mixed oxide catalysts prepared from hydrotalcite-like precursors on catalytic decomposition of $\mathrm{N}_{2} \mathrm{O}$. Catal Today 2007;119(1-4):233-8.

[25] Lamonier JF, Boutoundou AB, Gennequin C, Pérez-Zurita MJ, Siffert S, Aboukais A. Catalytic removal of toluene in air over Co-Mn-Al nano-oxides synthesized by hydrotalcite route. Catal Lett 2007;118:165-72.

[26] Buchholz S, Michele V, Mleczko M, Muennich C, Rudolf R, Wolf A. Process for continuously preparing catalysts. International patent 093337A2, 2007.

[27] Tessonnier JP, Becker M, Xia W, Girgsdies F, Blume R, Yao L, Su DS, Muhler M, Schlögl R. Spinel-type cobaltmanganese-based mixed oxide as sacrificial catalyst for the high-yield production of homogeneous carbon nanotubes. ChemCatChem 2010;2(12):1559-61. 
[28] Monti DAM, Baiker A. Temperature-programmed reduction: parametric sensitivity and estimation of kinetic parameters. J Catal 1983;83(2):323-35.

[29] Sadezky A, Muckenhuber H, Grothe H, Niessner R, Pöschl U. Raman microspectroscopy of soot and related carbonaceous materials: spectral analysis and structural information. Carbon 2005;43(8):1731-42.

[30] Bluhm H, Hävecker M, Knop-Gericke A, Kiskinova M, Schlögl R, Salmeron M. In situ X-ray photoelectron spectroscopy studies of gas-solid interfaces at near-ambient conditions. MRS Bulletin 2007;32:1022-30.

[31] Neimark A, Sing K, Thommes M. Handbook of heterogeneous catalysis. 2nd ed.Wiley- VCH, Weinheim, 2008:721-38.

[32] Yoo JS, Bhattacharyya AA, Radlowski CA. De-SO ${ }_{x}$ catalyst: an xrd study of magnesium aluminate spinel and its solid solutions. Ind Eng Chem Res 1991;30(7):1444-8.

[33] Vila E, Rojas RM, de Vidales JLM, García-Martínez O. Structural and thermal properties of the tetragonal cobalt manganese spinels $\mathrm{Mn}_{\mathrm{x}} \mathrm{CO}_{3-\mathrm{x}} \mathrm{O}_{4}(1.4<\mathrm{x}<2.0)$. Chem Mater 1996;8(5):1078-83.

[34] Swoboda T, Toole R, Vaughan J. New magnetic compounds of the ilmenite-type structure. J Phys Chem Solids 1958;5(4):293-8.

[35] Haggerty SE. Oxide minerals, reviews of mineralogy. vol 3. Amer Mineral Soc, 1976:6- 88.

[36] Waychunas GA. Oxide Minerals: petrologic and magnetic significance. vol 25. Amer Mineral Soc, 1991:11-53.

[37] Wang $\mathrm{HY}$, Ruckenstein E. $\mathrm{CO}_{2}$ reforming of $\mathrm{CH}_{4}$ over $\mathrm{Co} / \mathrm{MgO}$ solid solution catalysts effect of calcination temperature and Co loading. Appl Catal A: General 2001;209(1-2):207-15.

[38] Arnoldy P, Moulijn JA. Temperature-programmed reduction of $\mathrm{CoO} / \mathrm{Al}_{2} \mathrm{O}_{3}$ catalysts. J Catal 1985;93(1)38-54.

[39] Klissurski DG, Uzunova EL. Cation-deficient nanodimensional particle size cobalt-manganese spinel mixed oxides. Appl Surf Sci 2003;214(1-4):370-4.

[40] Goodenough JB, Loeb AL. Theory of ionic ordering, crystal distortion, and magnetic exchange due to covalent forces in spinels. Phys. Rev. 1955;98(2):391-408.

[41] He W, Zhang Y, Zhang X, Wang H, Yan H. Low temperature preparation of nanocrystalline $\mathrm{Mn}_{2} \mathrm{O}_{3}$ via ethanol-thermal reduction of $\mathrm{MnO}_{2}$. J Cryst Growth 2003;252(1-3):285-8.

[42] Irani K, Sinha A, Biswas A. Crystal distortion in spinels containing $\mathrm{Mn}^{3+}$ ions. J Phys Chem Solids 1960;17(12):101-11.

[43] Kapteijn F, Singoredjo L, Andreini A, Moulijn J. Activity and selectivity of pure manganese oxides in the selective catalytic reduction of nitric oxide with ammonia. Appl Catal B: Environmental 1994;3(2-3):173-89.

[44] Cheung CL, Kurtz A, Park H, Lieber CM. Diametercontrolled synthesis of carbon nanotubes. J Phys Chem B 2002;106(10):2429-33.

[45] Jodin L, Dupuis AC, Rouvière E, Reiss P. Influence of the catalyst type on the growth of carbon nanotubes via methane chemical vapor deposition. J Phys Chem B 2006;110(14):7328-33.

[46] Kundu S, Xia W, Busser W, Becker M, Schmidt DA, Havenith M, Muhler M. The formation of nitrogencontaining functional groups on carbon nanotube surfaces: a quantitative xps and tpd study. Phys Chem Chem Phys 2010;12:4351-9.
[47] Tuinstra F, Koenig JL. Raman spectrum of graphite. J Chem Phys 1970;53(3):1126-30

[48] Rao AM, Richter E, Bandow S, Chase B, Eklund PC, Williams KA, Fang S, Subbaswamy KR, Menon M, Thess A, Smalley RE, Dresselhaus G, Dresselhaus MS. Diameter-selective raman scattering from vibrational modes in carbon nanotubes. Science 1997;275:187-91.

[49] Wang Y, Alsmeyer DC, McCreery RL. Raman spectroscopy of carbon materials: structural basis of observed spectra. Chem Mater 1990;2(5):557-63.

[50] Sze SK, Siddique N, Sloan JJ, Escribano R. Raman spectroscopic characterization of carbonaceous aerosols. Atmos Environ 2001;35(3):561-8.

[51] Landi BJ, Cress CD, Evans CM, Raffaelle RP. Thermal oxidation profiling of single-walled carbon nanotubes. Chem Mater 2005;17(26):6819-34.

[52] McKee GSB, Vecchio KS. Thermogravimetric analysis of synthesis variation effects on cvd generated multiwalled carbon nanotubes. J Phys Chem B 2006;110(3):1179-86.

[53] Bom D, Andrews R, Jacques D, Anthony J, Chen B, Meier MS, Selegue JP. Thermogravimetric analysis of the oxidation of multiwalled carbon nanotubes: evidence for the role of defect sites in carbon nanotube chemistry. Nano Lett 2002;2(6):615-9.

[54] Schlögl R. Handbook of heterogeneous catalysis. 2nd ed. Wiley-VCH, Weinheim, 2008:357-427.

[55] Kobayashi Y, Sano M. Catalytic effects on thermal oxidation of single-walled carbon nanotubes by alkali metal chlorides. ChemCatChem 2010;2(4):397-401.

[56] Asokan K, Jan JC, Rao KVR, Chiou JW, Tsai HM, Mookerjee S, Pong WF, Tsai MH, Kumar R, Husain S, Srivastava JP. Electron- and hole-doping effects on the electronic structure of manganite studied by x-ray absorption spectroscopy. J Phys: Condens Matter 2004;16(21):3791-9.

[57] Radhakrishnan R, Oyama ST, Chen JG, Asakura K. Electron transfer effects in ozone decomposition on supported manganese oxide. J Phys Chem B 2001;105(19):4245-53.

[58] Thakur P, Chae KH, Kim JY, Subramanian M, Jayavel R, Asokan K. X-ray absorption and magnetic circular dichroism characterizations of $\mathrm{Mn}$ doped $\mathrm{ZnO}$. Appl Phys Lett 2007;91(16):162503-3.

[59] de Groot FMF. X-ray absorption and dichroism of transition metals and their compounds. J Electron Spectrosc Relat Phenom 1994;67(4):529-622.

[60] Nagel M, Biswas I, Peisert H, Chassé T. Interface properties and electronic structure of ultrathin manganese oxide films on $\mathrm{Ag}(000$ 1). Surf Sci 2007;601(18):4484-7.

[61] Cramer SP, DeGroot FMF, Ma Y, Chen CT, Sette F, Kipke CA, Eichhorn DM, Chan MK, Armstrong WH. Ligand field strengths and oxidation states from manganese 1-edge spectroscopy. J Am Chem Soc 1991;113(21):793740.

[62] Grush MM, Chen J, Stemmler TL, George SJ, Ralston CY, Stibrany RT, Gelasco A, Christou G, Gorun SM, Penner-Hahn JE, Cramer SP. Manganese l-edge Xray absorption spectroscopy of manganese catalase from lactobacillus plantarum and mixed valence manganese complexes. J Am Chem Soc 1996;118(1):65-9.

[63] Kuras M, Petit P, Petit C. Correlation between the characteristics of multi-wall carbon nanotubes and the structure of the metal oxides used as catalytic precursors for their production. Carbon 2011;49(4):1453-61. 